\title{
دراسه اقتصادية تحليلية للناتج المحلي الزراعى المصرى \\ فى ظل المتغيرات المحلية والاقليمية والدولية
}

\author{
شموع عوض محمد سليمان عرابي

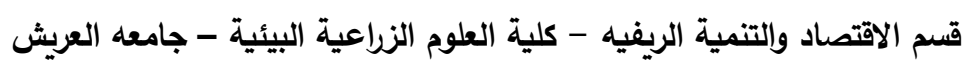

Received: Sep. 15 , 2020

Accepted: Oct. 19,2020

(الملخص:

يهرف هذا البحث بصفه عامه إلى التعرف على أداء القطاع الزراعى المصرى من خلال دراسه الوضع الراهن للناتج المحلى الزراعى وتحديد أهم العوامل المؤثره عليه.

وفيما يتعلق بمحدات الناتج المحلى الزراعى أشارت النتائج إلى أن أهم العوامل المؤثره على قيمة الناتج المحلي

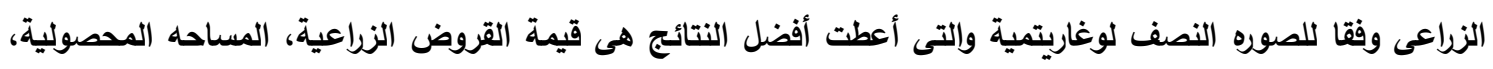
قيمة الصادرات الزراعية.

حيث أن زيادة هذه المتغيرات بمقدار الوحده فإن ذلك يؤدى إلى زيادة الناتج المحلي الزراعى بنسبه 0.28٪

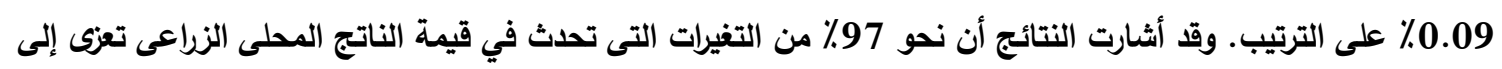
التغيرات على العوامل الثثلاثه متجمعه.

وفى ضوء هذه النتائج يوصى البحث بما يلى:

1. الاستمرار فى تنفيذ السياسات والبرامج والخطط الهادفه إلى استصلاح المزيد من الأراضى الزراعية (التوسع الأفقى) بهاف زيادة كل من المساحه المزورعه والمحصولية، ومن ثم الناتج المحلى الزراعى.

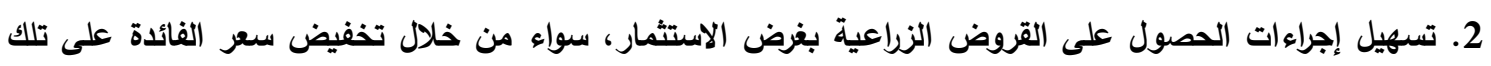
القروض، العمل فى تحسين المناخ الاستثمارى وجذب المزيد من الاستثمارات المحلية والأجنيية.

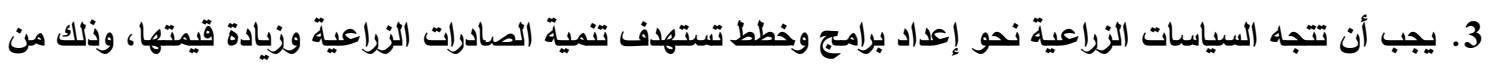

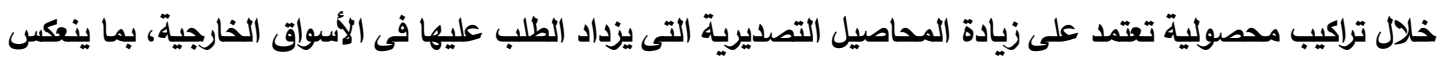

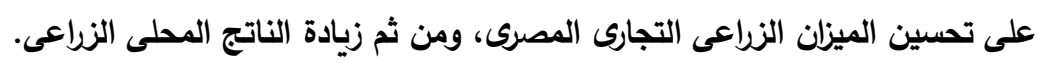
الكلمات المفتاحية: الناتج المحلى الزراعى، المؤشرات الاقتصادية، الزراعة المصرية، المتغيرات الاقتصادية.

أساس لمعظم الصناعات، بالأضافه إلى انه المسئول الأول مقدمه:

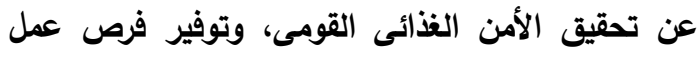

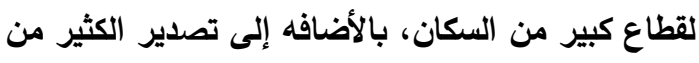

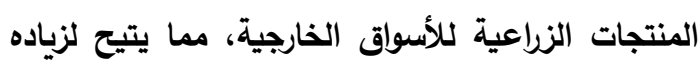

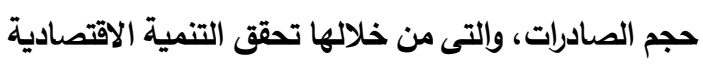
فى القطاعات الأخرى.

يمثل القطاع الزراعى المصرى عصب الاقتصاد القومى وركيزته الأساسية، وهو من أهم القطاعات الاقتصادية

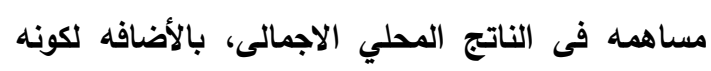

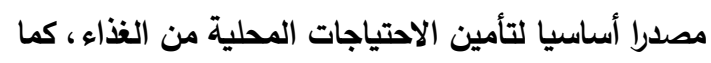

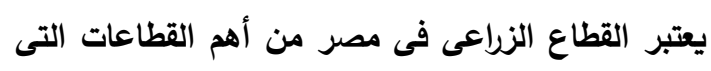

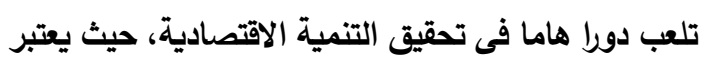




$$
\text { أهداف البحث: }
$$

يهذف البحث بصفه عامه التعرف على أداء القطاع الزراعى المصرى من خلال دراسه الوضع الراهن للناتج

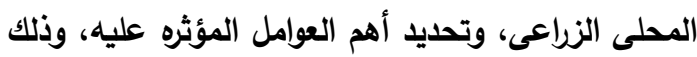
من خلال الأهداف الفرعية التالية: 1. دراسه تطور قيمة الناتج المحلي الإجمالى والناتج المحلي الزراعى، وأهميته النسبية فى الناتج الاجمالى.

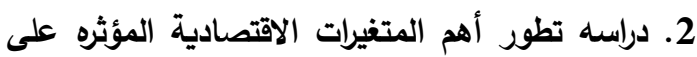

$$
\text { الناتج المحلي الزراعى. }
$$

3. استعراض النماذج القياسية البسيطه فى الصور لزعراعي المختلفه لعلاقه الناتج المحلي الزراعى بمحدداته.

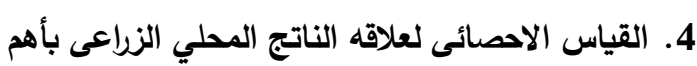
العوامل المؤثره عليه فى صوره المختلفة.

$$
\text { الأسلوب البحثى ومصادر جمع البيانات: }
$$

اعتمد البحث فى تحقيق أهدافه علي أسلوب التحليل

الوصفى والكمى، من خلال استخدام المقاييس البسيطه كالنسب المئوية والمتوسطات فى توصيف المتغيرات الاقتصادية، كما إعتمد على معادلات الإتجاه الزمنى العام لاراسه تطور تلك المتغيرات. كما اعتمد البحث بصفه أساسية على استخدام نماذج الانحدار المتعدد فى صورها

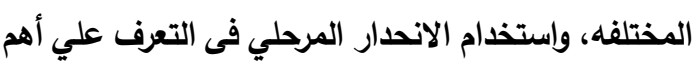

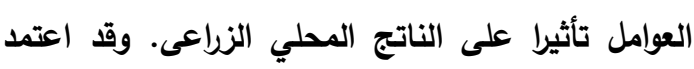
البحث علي البيانات الثانوية المنشوره الصادره من الجهاز المركزى للتعبئه العامه والاحصاء، ونشرات البنك المركزى لئي المصرى، بالاضافه إلى البيانات الثانوية غير المنشوره والتى يتم الحصول عليها من شبكه الاتصالات والمعلومات الدولية مثل موقع وزاره التخطيط، موقع مجلس الوزراء

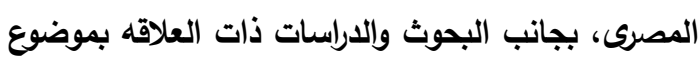

$$
\text { البحث. }
$$

ويعتبر الناتج المحلي الزراعى من أهم المؤاشرات

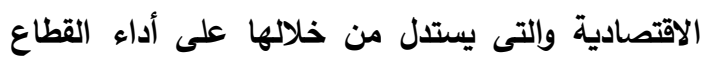

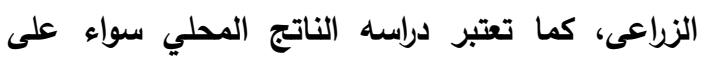
المستوى القومى أو المستوى القطاعى من الأهمية بمكان

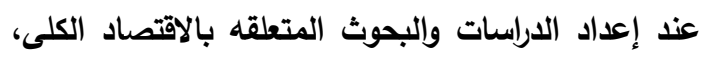
وعن حركه التدفقات النقدية والمدخلات وإلمخرجات وغيرها

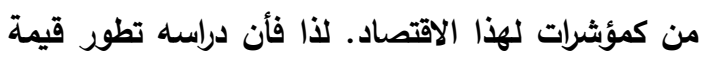
الناتج المحلي الزراعى والتعرف علي أهم المتغيرات

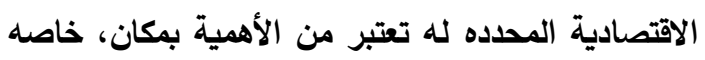

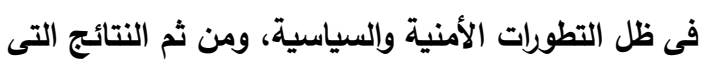
تنعكس علي الاقتصاد المصرى بصفه عامه والقطاع الزراعى بصفه خاصه. هذا وقد بلغت قيمة الناتج المحلى الزعل

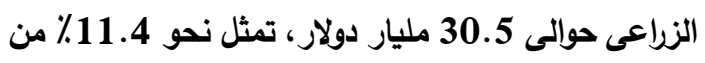
إجمالى الناتج القومى والبالغ نحو 266.8 مليار دولار خلال متوسط الفتره (2014 - 2018).

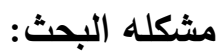

تعرض الاقتصاد المصرى فى الأونه الأخيره للعديد من

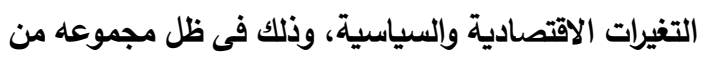

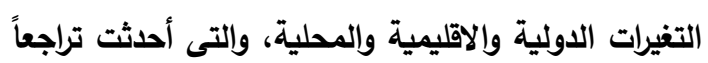

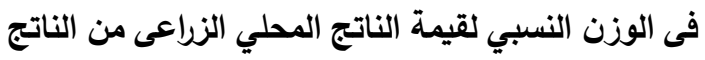

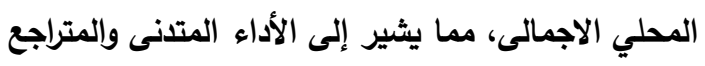

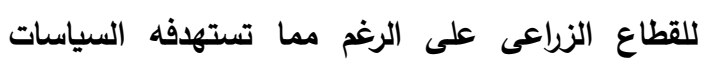
الاقتصادية والخطط التنموية الثامله لتعزيز بنيه الاقتصاد الرغاد المصرى بمختلف قطاعاته.

وتنحصر مشكله البحث قى الانخفاض المستمر لمساهمه الناتج المحلى الزراعى فى الناتج المحلي

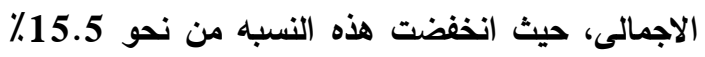
عام 2000 إلى نحو 11.2\% عام 2018، كما تمثل المشكله أيضاً فى أنه على الرغم من الاهتمام والجهود

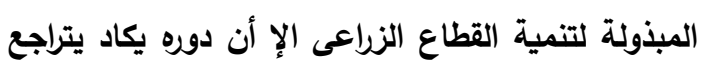
ويتسم بالضعف والتحيز والتهميش، وذلك لعدم مسايره

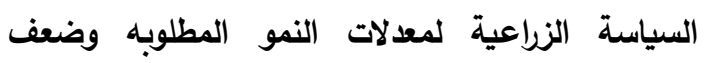
وإنخفاض نصيب قطاع الزراعه من إجمالى الاستثمارات. 
Analytical economic study of the Egyptian agricultural GDP in light of local, ........

(1-1) تطور الناتج المحلي الاجمالى.

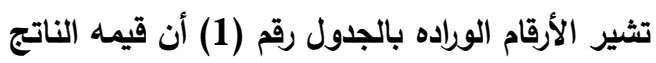

المحلي الاجمالي بلغت أدنى قيمة لها حوالى الهار مليار دولار خلال عام 2003، في حين بلغت أقصى قيمة

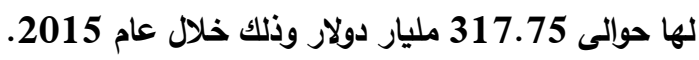

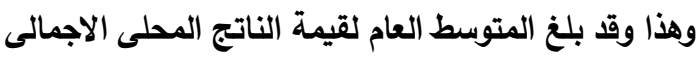

$$
\text { حوالى } 180.80 \text { مليار دولار. }
$$

مناقشه نتائج البحث

أولاً: الوضع الراهن للناتج المحلي الاجمالي والزراعي

فى مصر

يوضح الجدول رقم (1) تطور قيمة الناتج المحلي

الاجمالي والززاعي فى مصر وأهمية الناتج المحلى الزراعي

في الناتج الإجمالى حيث يتبين:

جدول رقم (1) : قيمة الناتج المحلي الإجمالي والناتج المحلي الزراعي والاهمية النسبية للناتج المحلي الزراعي في الاجمالي خلال الفترة 2018/2000

\begin{tabular}{|c|c|c|c|}
\hline الاهمية النسبية للناتج المحلي الزراعي & $\begin{array}{c}\text { قيمة الناتج المحلي الزراعي } \\
\text { (مليار دولار) }\end{array}$ & قيمة الناتج المحلي الاجمالي & السنة \\
\hline 15.54 & 15.22 & 97.95 & 2000 \\
\hline 15.35 & 13.86 & 90.28 & 2001 \\
\hline 15.40 & 12.97 & 84.21 & 2002 \\
\hline 15.29 & 10.91 & 71.36 & 2003 \\
\hline 14.27 & 11.18 & 78.32 & 2004 \\
\hline 13.98 & 13.03 & 93.18 & 2005 \\
\hline 13.24 & 14.26 & 107.74 & 2006 \\
\hline 13.42 & 17.74 & 132.16 & 2007 \\
\hline 12.63 & 20.82 & 164.84 & 2008 \\
\hline 13.00 & 24.43 & 187.97 & 2009 \\
\hline 13.34 & 28.63 & 214.62 & 2010 \\
\hline 13.87 & 32.05 & 231.10 & 2011 \\
\hline 11.27 & 31.17 & 276.53 & 2012 \\
\hline 11.27 & 30.53 & 270.79 & 2013 \\
\hline 11.34 & 34.12 & 300.95 & 2014 \\
\hline 11.40 & 36.21 & 317.75 & 2015 \\
\hline 11.77 & 31.81 & 270.25 & 2016 \\
\hline 11.48 & 22.41 & 195.14 & 2017 \\
\hline 11.23 & 28.08 & 250.14 & 2018 \\
\hline 13.11 & 22.60 & 180.80 & المتوسط \\
\hline
\end{tabular}

المصدر :

1- الجهاز المركزي للتعبئة العامة والاحصاء , الكتاب الاحصائي السنوي, اعداد متفرقة.

2-البنك الدولي - شبكة المعلومات الدولية. 
الزمن، كما تثير نسبه ف المحسوبه (39.14) إلى مدى مطابقه النموذج المستخدم لطبيعية البيانات موضع نديه القياس.

(3-1) الأهمية النسبية للناتج المحلي الزراعي فى

$$
\text { الناتج الإجمالي }
$$

تثير الأرقام الوراده بالجدول رقم (1) أن نسبه الناتج

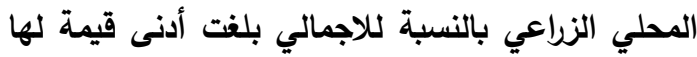

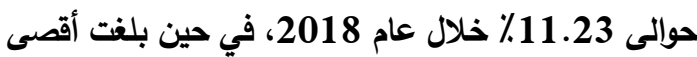
قيمة لها حوالى 15.54٪، وذلك خلال عام 2000. هذام وقد بلغ المتوسط العام حوالى13.11، 13. ويتضح أن الأهيه النسبية تتناقصت من حوالىى15.54\% عام 2000 الى حوالى 13.34\% عام 2010.، ثم تناقصت الى حوالى 11.23 عام 2018.

ثانياً: تطور أهم المتغيرات الإقتصادية المرتبطه بالناتج المحلي الزراعى في مصر . يستعرض هذا الجزء من الاراسه تطور أهم المتغيرات

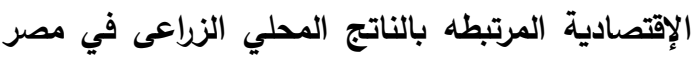
خلال الفتره (2000- 2018) ومنه يتبين:
كما تثير تقديرات المعادله رقم (1) فى جدول رقم (2) ان الناتج المحلي القومى يتزايد بمقدار معنوى إحصائيا بلغ

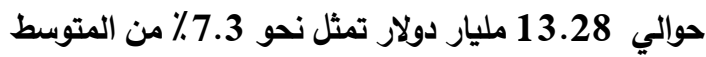
العام خلال تلك الفتره. وتثير قيمة معامل التحديد ان

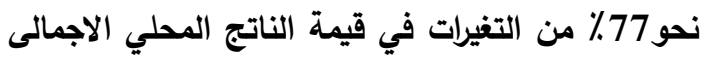
تعزى إلي عامل الزمن، كما تثير نسبه ف المحسوبه (58.39) إلى مدى مطابقه النموذج المستخدم لطبيعية البيانات موضع القياس.

$$
\text { (2-1) تطور الناتج المحلي الزراعى. }
$$

بلغ الناتج المحلي الزراعى أدنى قيمة له حوالى لهى 10.91 مليار دولار خلال عام 2003، في حين بلغت أقصى قيمة له حوالى 36.21 مليار دولار وذلك خلال عام

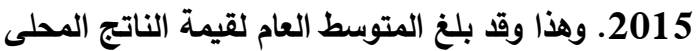
الزراعى حوالى 22.60 مليار دولار. كما تثير تقديرات المعادله رقم (2) فى جدول رقم (2) ان الناتج المحلي الزراعى يتزايد بمقدار معنوى إحصائيا بلغ حوالي 1.29

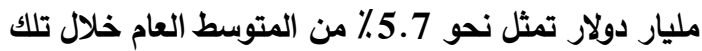

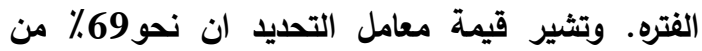
التغيرات في قيمة الناتج المحلي الزراعى تعزى إلي عامل

جدول رقم (2): الاتجاه الزمني العام لتطور قيمة الناتج المحلي الإجمالي والناتج المحلي الزراعي والأهمية النسبية للناتج

\begin{tabular}{|c|c|c|c|c|c|}
\hline $\mathbf{F}$ & $\mathbf{R}^{2}$ & ا ب التغير السنوي & معادلات الاتجاة الزمني العام & المتغيرات & رق المعادلة \\
\hline 58.39 & 0.77 & 7.3 & $\begin{aligned} \hat{\mathbf{Y}}= & 48.05+13.28 \mathrm{~T}_{\mathbf{i}} \\
& (2.42)^{*} \quad(7.64)^{* *}\end{aligned}$ & $\begin{array}{c}\text { قيمة الناتج المحلي الإجمالي } \\
\text { ( مليار دولار) }\end{array}$ & 1 \\
\hline 39.14 & 0.69 & 5.7 & $\begin{array}{l}\hat{\mathbf{Y}}=9.63+1.29 \mathrm{~T}_{\mathrm{i}} \\
(4.07)^{* *}(6.25)^{* *}\end{array}$ & $\begin{array}{c}\text { قيمة الناتج المحلي الزراعي } \\
\text { ( مليار دولار) }\end{array}$ & 2 \\
\hline 105.03 & 0.86 & 2.0 & $\begin{array}{lc}\hat{\mathrm{Y}}=15.71 & -0.26 \mathrm{~T}_{\mathrm{i}} \\
(54.28)^{* * *} & (-10.24)^{* * *}\end{array}$ & الألهية النسبية للناتج & 3 \\
\hline
\end{tabular}
المحلي الزراعي في الاجمالي خلال الفترة 2018/2000

المصدر: جمعت وحسبت من الأرقام الواردة بالجدول رقم (1) . 
Analytical economic study of the Egyptian agricultural GDP in light of local, .......

$$
\text { (2-3) (2-3) حجم العماله الزراعية: }
$$

تثير الأرقام الوراده بالجدول رقم (3) أن حجم العماله

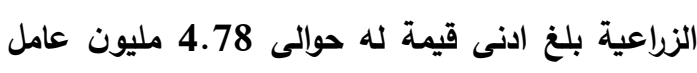

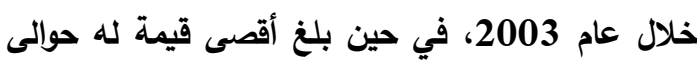

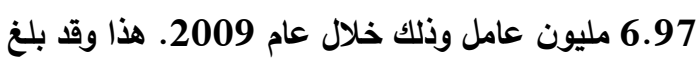

المتوسط العام لحجم العماله الزراعية حوالى 6.11 مليون عليون

$$
\text { عامل. }
$$

وتوضح المعادله رقم (6) الاتجاه الزمنى العام لتطور

حجم العماله الزراعية فى مصر خلال الفتره من 2000 - 2018 2018. حيث يتبين ان حجم العماله الزراعية تتزايد سنويا

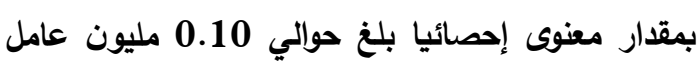

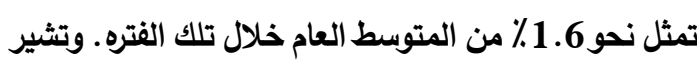

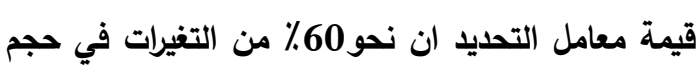

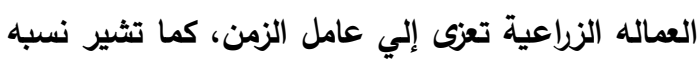
ف المحسوبه (25.70) إلى مدى مطابقه النموذج المستخدم لطبيعية البيانات موضع القياس.

(2-4) (المساحة المحصولية: تثير الأرقام الوراده بالجدول رقم (3) أن المساحة المحصولية بلغت ادنى قيمة لها حوالى 13.35 مليون فدان خلال عام 2002، في حين بلغ أقصى قيمة له حوالى 16.28 مليون فدان وذلك خلال عام 2018. وهذان وقد بلغ المتوسط العام لحجم العماله الزراعية حوالى فلى 16. 15.12 مليون فدان.

وتوضح المعادله رقم (7) الاتجاه الزمنى العام لتطور

المساحة المحصولية فى مصر خلال الفتره من 2000 - 2018 2018. حيث يتبين ان المساحة المحصولية تتزيد سنويا بمقدار معنوى إحصائيا بلغ حوالي 0.12 مليون فدان تمثل نحو0.79٪ من المتوسط العام خلال تلك الفتره. وتشير

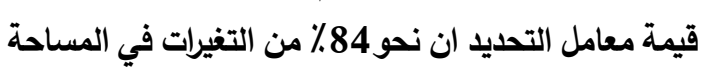

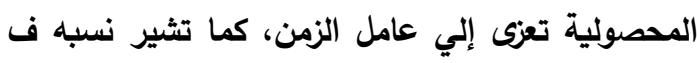
المحسوبه (91.97) إلى مدى مطابقه النموذج المستخدم لطبيعية البيانات موضع القياس.
(2-1) تطورالاستثمارات الزراعية:

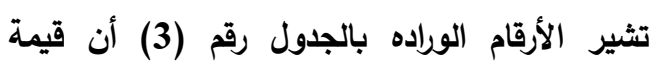
الاستثمارات الزراعية بلغت أدنى قيمة لها حوالى الجارول

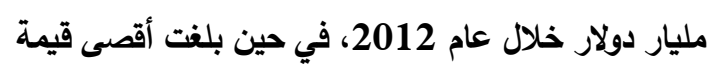
لها حوالى 2.34 مليار دولار وذلك خلال عام 2000. وهذا وقد بلغ المتوسط العام لقيمة الاستثمارات الزراعية حوالى 1.45 مليار دولار. وتوضح المعادله رقم (4) بالجدول رقم (4) الاتجاه الزمنى العام لتطور قيمة الاستثمارات الزراعية فى مصر البرل

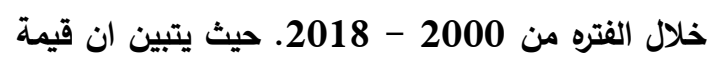
الاستثمارات الزراعيه تناقص سنويا بمقدار غير معنوى

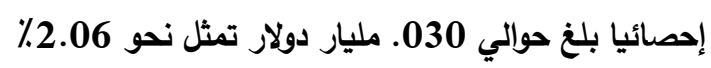

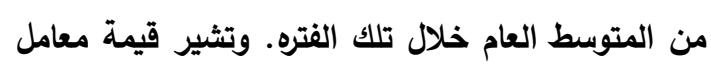
التحديد ان نحو18\% من التغيرات في قيمة الاستثمارات

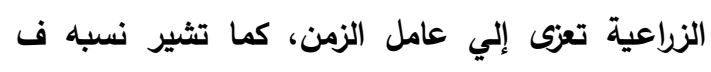
المحسوبه (3.94) إلى مدى مطابقه النموذج المستخدم لطبيعية البيانات موضع القياس. (2-2) قيمة القروض الزراعية: تثير الأرقام الوراده بالجدول رقم (3) أن قيمة الزورة القروض الزراعية بلغت ادنى قيمة لها حوالى 0.72 مليار دولار خلال عام 2017، في حين بلغت أقصى قيمة لها

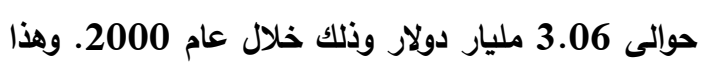
وقد بلغ المتوسط العام لقيمة القروض الزراعية حوالى دلى دلى دلام 2.21 مليار دولار. وتوضح المعادله رقم (5) بالجدول رقم (4) الاتجاه الزمنى العام لتطور قيمة القروض الزراعية فى مصر خلال

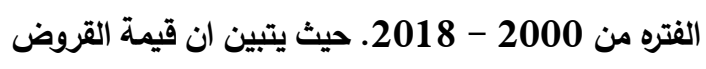
الزراعية تتناقص سنويا بمقدار معنوى إحصائيا بلغ حوالي 0.071 مليار دولار تمثل نحو 3.21٪ من المتوسط العام

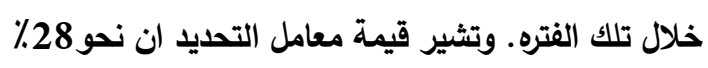
من التغيرات في قيمة القروض الزراعية تعزى إلي عامل

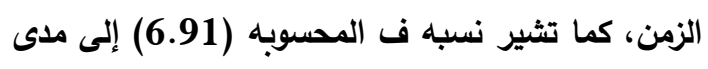
مطابقه النموذج المستخدم لطبيعية البيانات موضع لئه

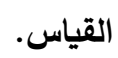




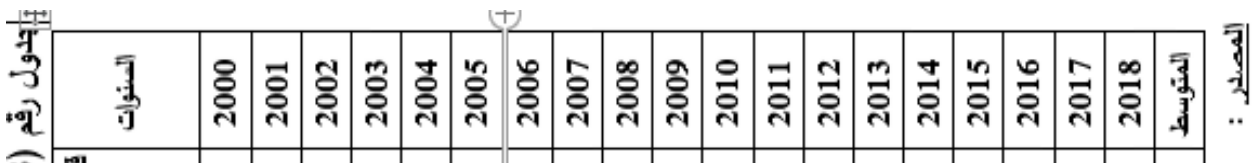

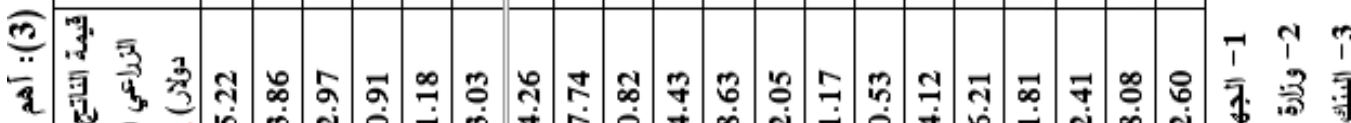

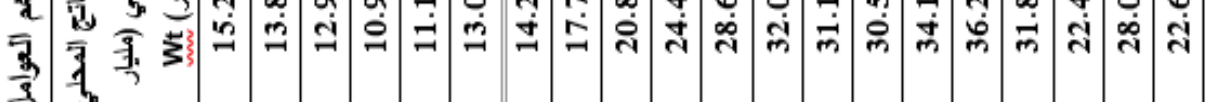

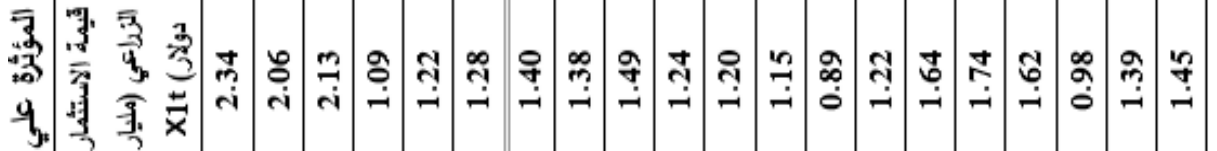

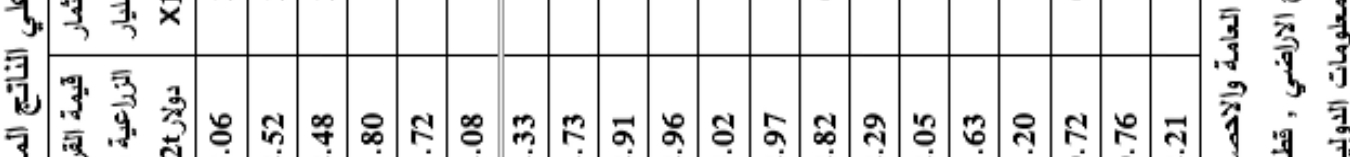

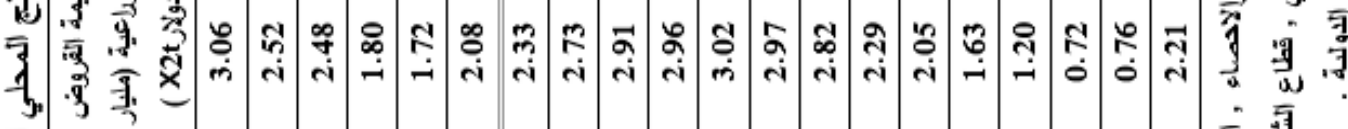

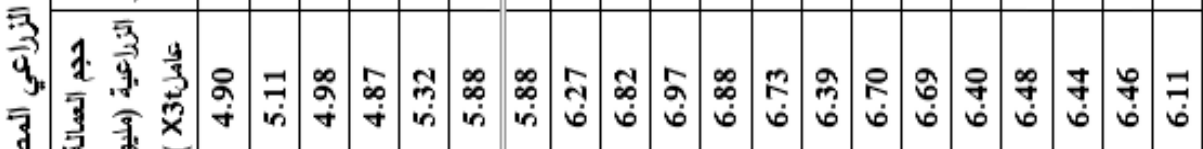

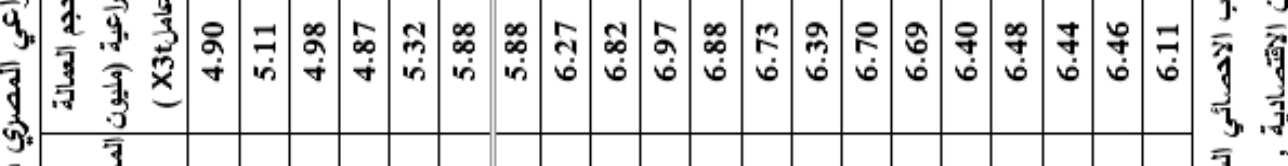

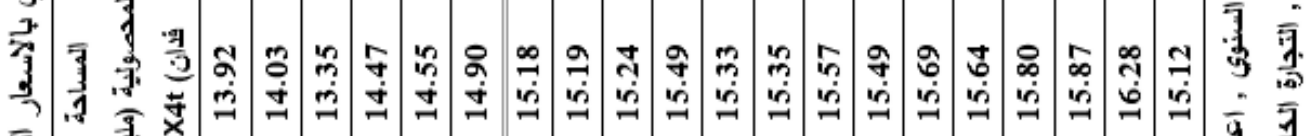

.

等

4 等

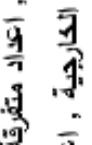

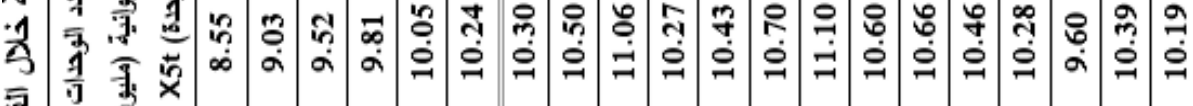
雷

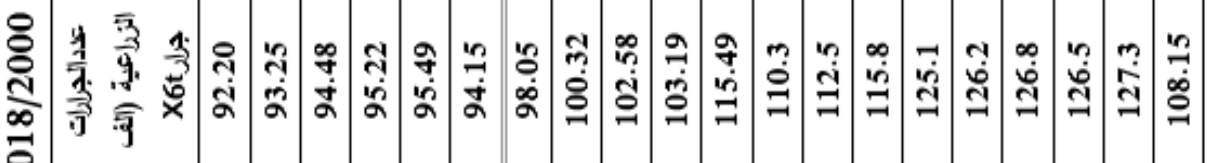
त

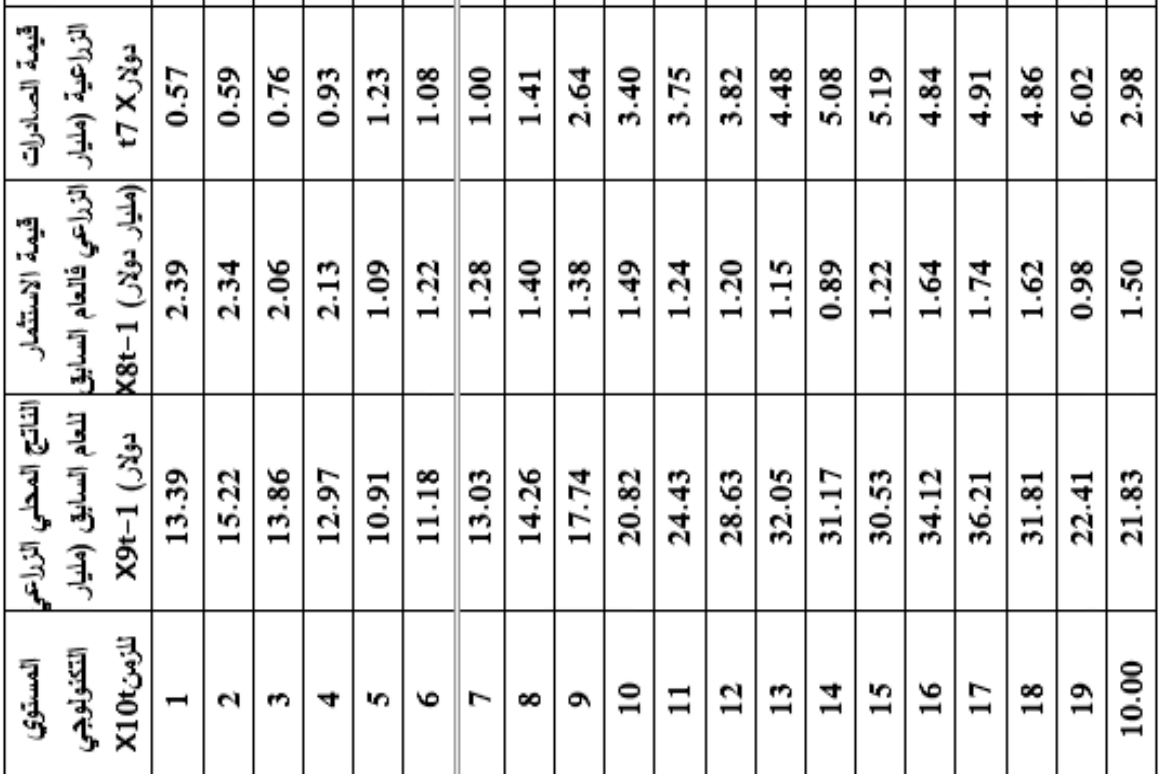


جدول (4): النماذج القياسية لمعادلات الاتجاه الزمني العام لتطور أهم المتغيرات الاقتصادية المرتبطه بالناتج المحلي

\begin{tabular}{|c|c|c|c|c|c|}
\hline ف & , & ا & المعادلة & البيان & المعادلة \\
\hline 3.94 & 0.18 & 2.06 & $\begin{array}{c}\hat{\mathrm{Y}}=1.748 \quad-.030 \mathrm{Ti} \\
(10.04)^{* * *}(-1.985)\end{array}$ & 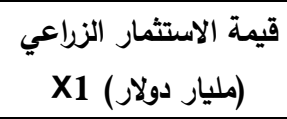 & 4 \\
\hline 6.91 & 0.28 & 3.21 & $\begin{array}{r}\hat{Y}=2.92-0.071 T_{i} \\
(9.48)^{* *}(-2.62)\end{array}$ & $\begin{array}{c}\text { قيمة القروض الزراعية) } \\
\text { X2 (مليار دولار) }\end{array}$ & 5 \\
\hline 25.70 & 0.60 & 1.63 & $\begin{array}{c}\hat{\mathbf{Y}}=5.11+0.10 \mathrm{~T}_{\mathrm{i}} \\
(22.74)^{* *} \quad(5.06)^{* *}\end{array}$ & جمجم العمالة الزراعية & 6 \\
\hline 91.97 & 0.84 & 0.79 & $\begin{array}{r}\hat{\mathbf{Y}}=13.89+0.12 \mathrm{~T}_{\mathrm{i}} \\
(95.51)^{* * *}(9.59)\end{array}$ & المساحة المحصولية & 7 \\
\hline 7.96 & 0.31 & 0.62 & $\begin{array}{rr}\hat{Y}= & 9.53+0.064 T_{i} \\
& (36.37)\end{array}$ & 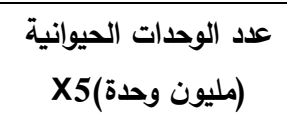 & 8 \\
\hline 232.16 & 0.93 & 2.10 & $\begin{array}{c}\hat{\mathbf{Y}}=85.26+2.28 \mathrm{~T}_{\mathrm{i}} \\
(49.77)^{* *}(15.23)^{* *}\end{array}$ & 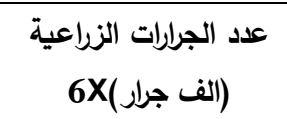 & 9 \\
\hline 216.2 & 0.92 & 10.73 & $\begin{array}{c}\hat{\mathbf{Y}}=-0.31+0.32 \mathrm{~T}_{\mathrm{i}} \\
(-1.24) \quad(14.7)^{* *}\end{array}$ & 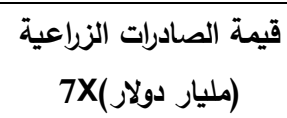 & 10 \\
\hline
\end{tabular}

\%5 معنوى عند "

\%1 معنوى عند:"*

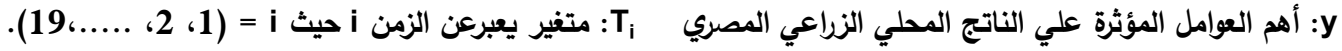

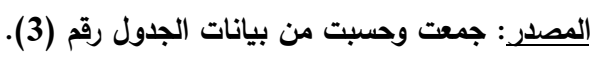

الزمن، كما تثير نسبه ف المحسوبه (7.96) إلى مدى

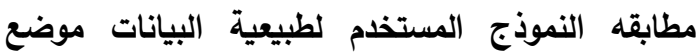
القياس.

(2-6) (2-6) عدد الجرارات الزراعية: تثير الأرقام الوراده بالجدول رقم (3) أن عدد الجرارات الزراعية بلغ أدنى قيمة له حوالى عام 2000، في حين بلغ أقصى قيمة له حوالى 127.3

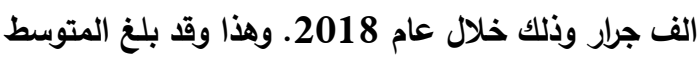
العام لعدد الوحدات الحيوانية حوالى 108.15 مليون

وحده.

وتوضح المعادله رقم (9) الاتجاه الزمنى العام لتطور عدد الجرارات الزراعية فى مصر خلال الفتره من 2000 - 2018. حيث يتبين ان عدد الجرارات الزراعية تتزايد
(5-5) عدد الوحدات الحيوانية: تثير الأرقام الوراده بالجدول رقم (3) أن عدد الوحدات الوحات الحيوانية بلغ ادنى قيمة لها حوالى8.55 مليون وحده خلال عام 2000، في حين بلغ أقصى قيمة له حوالى لهي 11.06 مليون وحده وذلك خلال عام 2008. وهذا وقد بلغ المتوسط العام لعدد الوحدات الحيوانية حوالى 10.19

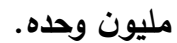
وتوضح المعادله رقم (8) بالجدول رقم (4) الاتجاه الزمنى العام لتطور عدد الوحدات الحيوانية فى مصر خلال الفتره من 2000 - 2018. حيث يتبين ان عدد الوحدات الحيوانية تتزايد سنويا بمقار معنوى إحصائيا بلغ حوالي 0.064 مليون وحده تمثل نحو 0.62\% من المتوسط العام خلال تلك الفتره . وتثير قيمة معامل التحديد ان نحو 31٪ من التغيرات في عدد الوحدات الحيوانية تعزى إلي عامل 
1- العلاقه بين الناتج الزراعى والمساحة المحصولية:

توضح المعادله رقم (14) العلاقه الخطية البسيطه بين

قيمة الناتج المحلي الزراعى كمتغير تابع والمساحه المحصولية كمتغير مستقل حيث يتبين وجود علاقه طردية مؤكده احصائيا بين قيمة الناتج المحلي الزراعى والمساحه

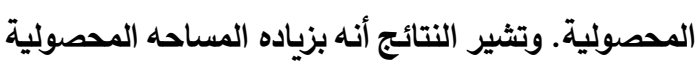
بحوالي مليون فدان فأن قيمة الناتج المحلي الزراعى تزايد بحوالي 8.65 مليون فدان، كما تثير قيمة معامل التحان التحديد

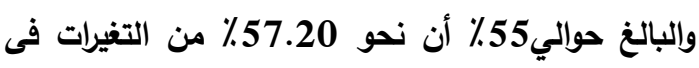

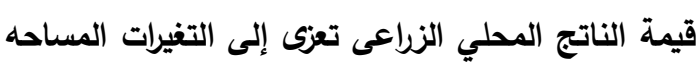

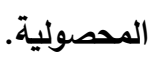

وتثير نسبه ف المحسوبه إلى مدى مطابقه النموذج

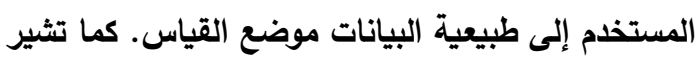
تقديرات المعادله رقم (22) فى جدول رقم (6) أن زيادة المساحه المحصولية بنسبه 10٪ تؤدى إلى زيادة قيمة

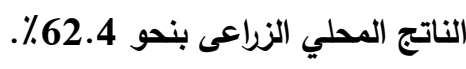

2- العلاقه بين الناتج الزراعى وعدد الوحدات

$$
\text { الحيوانية: }
$$

وتوضح المعادله رقم (15) العلاقه الخطية البسيطه

بين قيمة الناتج المحلي الزراعى كمتفير تابع وعداد

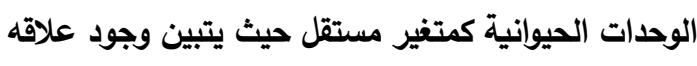
طردية مؤكده احصائيا بين قيمة الناتج المحلي الزراعى النى

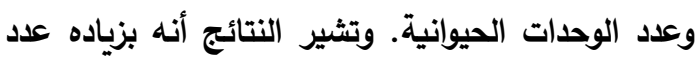

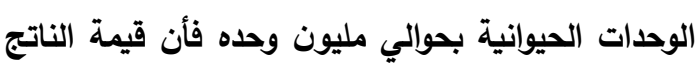
المحلي الزراعى تزايد بحوالي 7.82 مليون وحده، كما

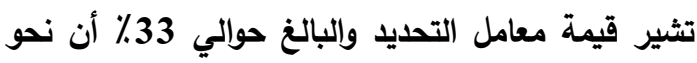

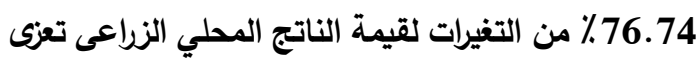
إلى التغيرات لعدد الوحدات الحيوانية.

وتثير نسبه ف المحسوبه إلى مدى مطابقه النموذج المستخدم إلى طبيعية البيانات موضع القياس.

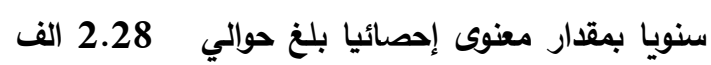
جرار تمثل نحو 2.10٪ من المتوسط العام خلال تلك الفتره. وتثير قيمة معامل التحديد ان نحو 93\% من التوبط التغيرات في عدد الجرارات الزراعية تعزى إلي عامل الزمن، كما تثير لئير نسبه ف المحسوبه (232.16) إلى مدى مطابقه النموذج المستخدم لطبيعية البيانات موضع القياس.

$$
\text { (2-7) الصادرات الزراعية: }
$$

تثير الأرقام الوراده بالجدول رقم (3) أن قيمة الصادرات الزراعية بلغت ادنى قيمة لها حوالى لئ 0.57

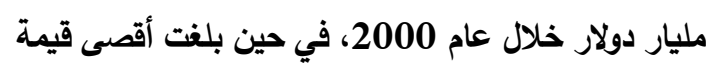
لها حوالى 6.02 مليار دولار وذلك خلال عام 2018. وهذا وقد بلغ المتوسط العام لقيمة الصادرات الزراعية حوالى 2.98 مليار دولار. وتوضح المعادله رقم (10) الاتجاه الزمنى العام لتطور

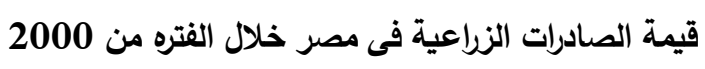
- 2018. حيث يتبين ان قيمة الصادرات الزراعيه تتزايد سنويا بمقدار معنوى إحصائيا بلغ حوالي 0.32 مليار

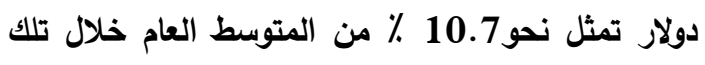

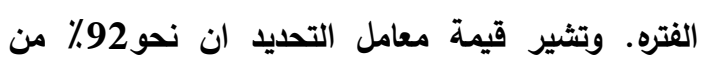

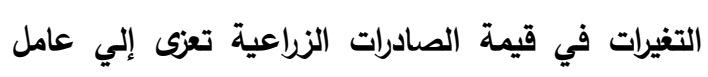

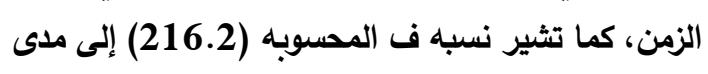
مطابقه النموذج المستخدم لطبيعية البيانات موضع لديه القياس.

ثالثاً: العلاقه الخطية بين الناتج المحلي الزراعى

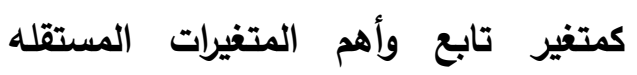
المرتبطه به. يوضح الجدول رقم (5) العلاقه الخطية بين الناتج المحلي الزراعى كمتغير تابع وأهم المتغيرات المستقله المرتبطه به، كما يوضح الجدول رقم (6) العلاقه الخطيه

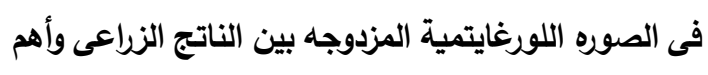
العوامل الزراعية حيث يتبين: 
Analytical economic study of the Egyptian agricultural GDP in light of local, ........

مؤكده احصائيا بين قيمة الناتج المحلي الزراعى وعدد

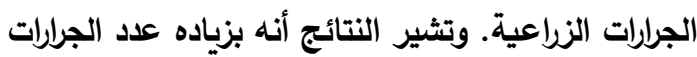

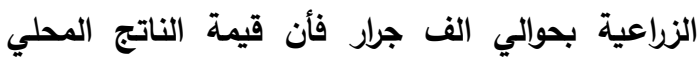

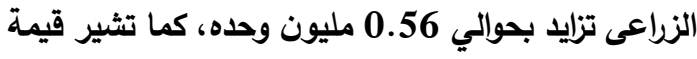

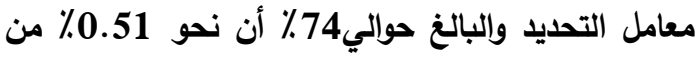

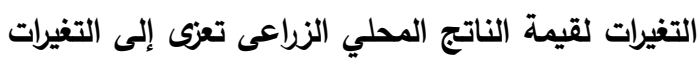

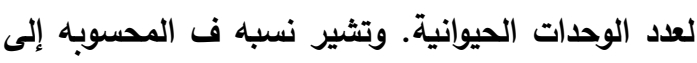

مدى مطابقه النموذج المستخدم إلى طبيعية البيانات

موضع القياس.
كما تثير تقديرات المعادله رقم (23) فى جدول رقم

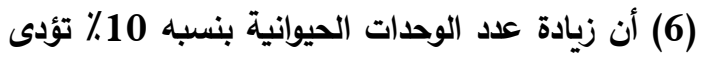

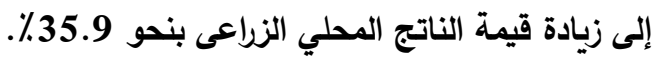

3- العلاقه بين الناتج الزراعى وعدد الجرارات

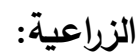

توضح المعادله رقم (16) العلاقه الخطية البسيطه بين

قيمة الناتج المحلي الزراعى كمتغير تابع وعدد الجرارات الزراعية كمتغير مستقل حيث يتبين وجود علاقه طردية النيا

جدول رقم (5): نتائج القياس الاحصائي لأهم العوامل المؤثرة علي الناتج المحلي الزراعي المصري بالاسعار الحقيقية باستخدام الصوره الخطية خلال الفتره (2000-2018)

\begin{tabular}{|c|c|c|c|c|}
\hline $\mathbf{F}$ & $\mathbf{R}^{2}$ & المعادلة & 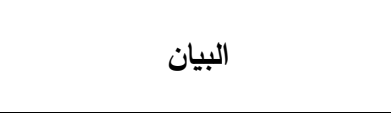 & المعادلة \\
\hline 0.808 & 0.21 & $\begin{array}{c}\hat{\mathrm{Y}}=29.45-4.73 \mathrm{x}_{1} \\
(3.73)^{* *} \quad(-.89)\end{array}$ & $\begin{array}{c}\text { قيمة الاستثمار الزراعي } \\
\text { (مليار دولار) }\end{array}$ & 11 \\
\hline 0.184 & 0.10 & $\begin{array}{c}\hat{\mathbf{Y}}=25.29-1.21 \mathrm{X}_{2} \\
(3.83)^{* *} \quad(-0.42)\end{array}$ & قيمة القروض الزراعية & 12 \\
\hline 26.60 & 0.61 & $\begin{array}{c}\hat{\mathbf{Y}}=-34.984+9.41 x_{3} \\
(-3.11)^{* *} \quad(5.15)^{* *}\end{array}$ & حجم العمالة الزراعية & 13 \\
\hline 20.86 & 0.55 & $\begin{array}{l}\hat{\mathbf{Y}}=-108.34+8.65 \times_{4} \\
(-3.77)^{* *} \quad(4.56)^{* *}\end{array}$ & المساحة المحصولية & 14 \\
\hline 8.54 & 0.33 & $\begin{array}{c}\hat{\mathbf{Y}}=-57.08+7.82 x_{5} \\
(-2.09)^{*} \quad(2.92)^{* * *}\end{array}$ & $\begin{array}{c}\text { عدد الوحدات الحيوانية } \\
\text { (مليون وحدة) }\end{array}$ & 15 \\
\hline 48.75 & 0.74 & $\begin{array}{l}\hat{\mathbf{Y}}=-38.42+.56 \mathrm{x}_{6} \\
(-4.36)^{* *}(6.98)^{* *}\end{array}$ & عدد الجرارات الزراعية (الف جرار) & 16 \\
\hline 232.16 & 0.82 & $\begin{array}{c}\hat{\mathbf{Y}}=10.36+4.11 x_{7} \\
(6.30)^{* *} \quad(8.80)^{* *}\end{array}$ & $\begin{array}{c}\text { قيمة الصادرات الزراعية } \\
\text { (مليار دولار ) }\end{array}$ & 17 \\
\hline 39.14 & 0.69 & $\begin{array}{l}\hat{\mathbf{Y}}=9.62+1.29 \mathrm{x}_{8} \\
(4.07)^{* *} \quad(6.25)^{* *}\end{array}$ & المستوى التكنولوجى للزمن & 18 \\
\hline
\end{tabular}

المصدر: جمعت وحسبت من بيانات الجدول رقم (3).

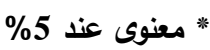
\%1 معنوى عند:"*

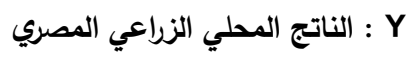

= X X X = X $=X_{6}$ . X X

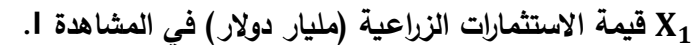
=X ع عد الوحدات الحيوانية (مليون وحده)في المشاهدة ال I قيمة الصادرت الزراعيه(مليار دولار) في المشاهدة 
جدول رقم (6): نتائج القياس الاحصائي لأهم العوامل المؤثرة علي الناتج المحلي الزراعي المصري بالاسعار الحقيقية

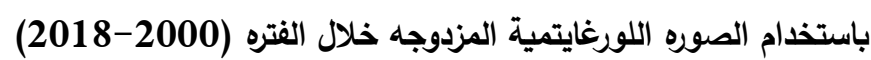

\begin{tabular}{|c|c|c|c|c|}
\hline $\mathbf{F}$ & $\mathbf{R}^{2}$ & المعادلة & 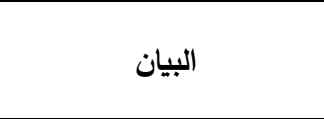 & 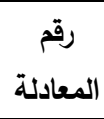 \\
\hline .0 .684 & 0.03 & 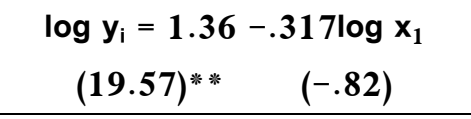 & قيمة الاستثمار الزراعي & 19 \\
\hline .0 .284 & 0.01 & $\begin{array}{rr}\log y_{i}=1.35-.122 \log x_{2} \\
(16.36)^{* *} \quad(-.53-)\end{array}$ & 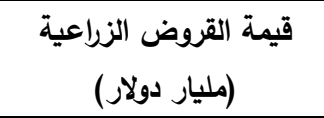 & 20 \\
\hline 36.043 & 0.68 & $\begin{array}{c}\log y i=-.84+2.76 \log x 3 \\
(-2.33)^{*} \quad(6.00)^{* *}\end{array}$ & $\begin{array}{c}\text { حجم العمالة الزراعية } \\
\text { (مليون عامل) }\end{array}$ & 21 \\
\hline 23.28 & 0.57 & $\begin{array}{c}\log y_{i}=-6.04+6.24 \log x_{4} \\
(-3.96)^{* *}(4.82)^{* *}\end{array}$ & $\begin{array}{c}\text { المساحة المحصولية } \\
\text { (مليون فدان) }\end{array}$ & 22 \\
\hline 8.04 & 0.32 & $\begin{array}{c}\log y_{i}=-2.29+3.59 \log x_{5} \\
(-1.80) \quad(2.83)^{*}\end{array}$ & 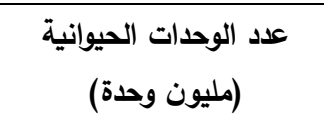 & 23 \\
\hline 53.27 & 0.75 & $\begin{array}{c}\log y_{i}=-4.71+2.97 \log x_{6} \\
(-5.70)^{* *}(7.29)^{* *}\end{array}$ & $\begin{array}{c}\text { عدد الجرارات الزراعية } \\
\text { (الف جرار) }\end{array}$ & 24 \\
\hline 78.81 & 0.82 & $\begin{array}{c}\log y_{i}=1.16+.44 \log x_{7} \\
(45.95)^{* * *} \quad(8.87)^{* * *}\end{array}$ & $\begin{array}{c}\text { قيمة الصادرات الزراعية } \\
\text { (مليار دولار) }\end{array}$ & 25 \\
\hline 24.63 & 0.59 & $\begin{aligned} \log y_{i} & =.963+.397 \log x_{8} \\
& (12.51)^{* *}(4.96)^{* * *}\end{aligned}$ & المستوى التكنولوجى للزمن & 26 \\
\hline
\end{tabular}

المصدر: جمعت وحسبت من بيانات الجدول رقم (3).

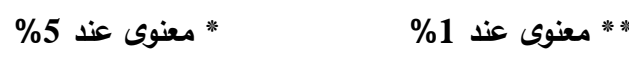

log yi

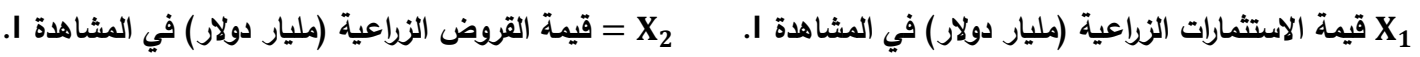

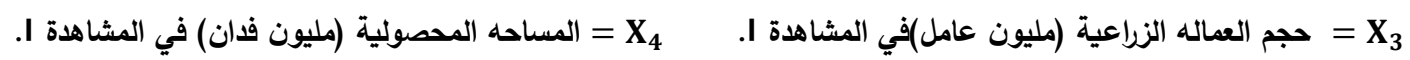

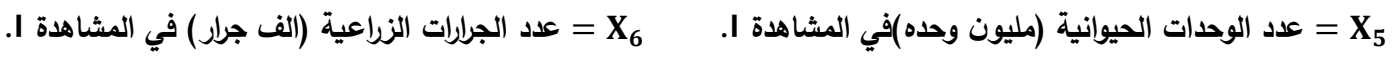

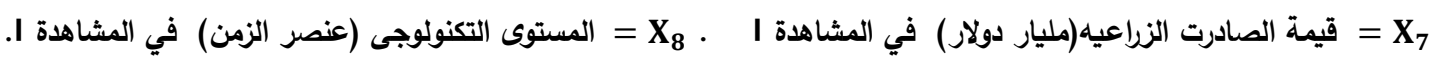

الصادرات الزراعيه كمتغير مستقل حيث يتبين وجود علاقه طردية مؤكده احصائيا بين قيمة الناتج المحلي لرئي الزراعى وقيمة الصادرات الزراعية. وتثير النتائج أنه بزياده قيمة الصادرات الزراعية بحوالي مليار دولار فأن قيمة الناتج المحلي الزراعى تزايد بحوالي 4.11 مليار

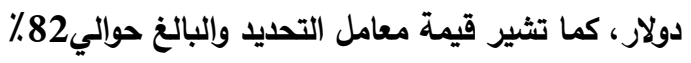
أن نحو 137.9٪ من التغيرات لقيمة الناتج المحلي الزراعى تعزى إلى التغيرات لقيمة الصادرات الزراعية.
كما تشير تقديرات المعادله رقم (24) فى جدول رقم (6) أن زيادة عدد الجرارات بنسبه 10 10 تؤدى إلى زيادة

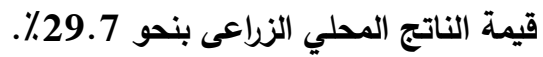
4- العلاقه بين الناتج الزراعى وقيمة الصادرات الزراعية: توضح المعادله رقم (17) العلاقه الخطية البسيطه بين قيمة الناتج المحلي الزراعى كمتغير تابع وقيمة 
9 - I الناتج المحلي الزراعى فى العام السابق بالمليار دولار $X_{9}$

X10 10

ووفقا لفروض النظرية الاقتصادية، فأن شكل العلاقة

بين قيمة الناتج المحلي الزراعى وكل من قيمة الاستثمارات

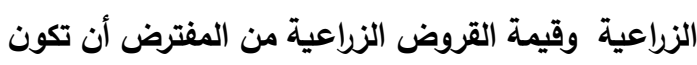
علاقه طردية (موجبه) على اعتبار أن الاستثمارات

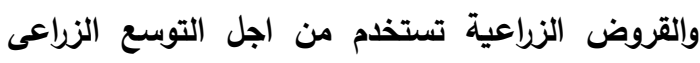

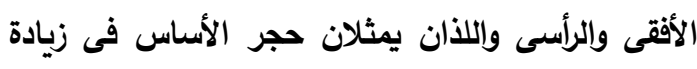
الناتج المحلي الزراعى. كذلك بالنسبه لعجم العماله الزراعية والمساحه المحصولية ، وعدد الوحدات الحيوانية وعدد الجرارات خيث تعتير من أهم عناصر الانتاج فى وعلى الوحات الهيل التنمية الزراعية والتى تؤدى إلى زياده كل من الإخل

$$
\text { الزراعى و الناتج المحلي الزراعى. }
$$

وحيث الصادرات الزراعية تعتبر أحد مصادر الاخل

الزراعى فأن العلاقه بينها وبين قيمة الناتج المحلي الزراعى هى علاقه طردية.

كما أن ارتفاع مستوى التقدم التكنولوجى يؤدى إلى

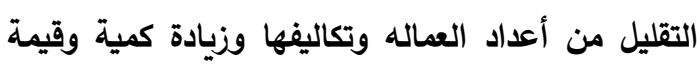
الانتاج الزراعى من خلال العمل والاستفاده من عوائد

السعه.

لتلافى مشكله الارتباط الخطى بين المتغيرات المستقله وتحديد أكثر العوامل تأثيرا على الناتج المحلي الزراعى فقد الأدي اعتمدت الدراسه علي استخدام طريقه الانحدار المرحلي Step Wise فى تقدير معادله الانحدار المتعدد

فى صورها المختلفه.

1- نتائج القياس الاحصائى للصوره الخطية توضح المعادله رقم (27) بالجدول رقم (7) إلى نتائج

القياس الاحصائى للعلاقه بين قيمة الناتج المحلي الزراعى لدالئ

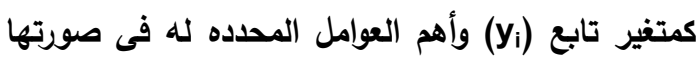

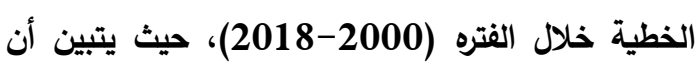
أكثر العوامل تأثيرا علي قيمة الناتج المحلي الزراعى هى:
وتثير نسبه ف المحسوبه إلى مدى مطابقه النموذج المستخدم إلى طبيعية البيانات موضع القياس. كما تثير تقديرات المعادله رقم (25) فى جدول رقم

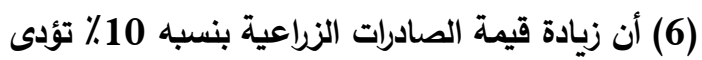

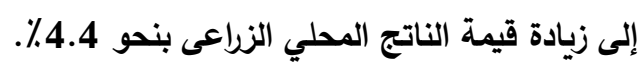
5- العلاقه بين الناتج الزراعى والمستوى التكنولوجى:

توضح المعادله رقم (18) العلاقه الخطية البسيطه بين قيمة الناتج المحلي الزراعى كمتغير تابع والمستوى التكنولوجى كمتغير مستقل حيث يتبين وجود علاقه طردية النيات

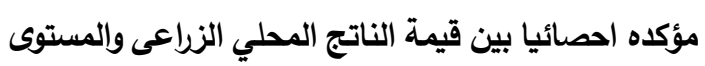

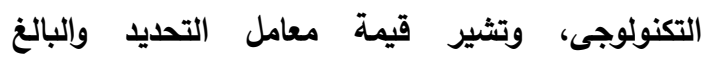

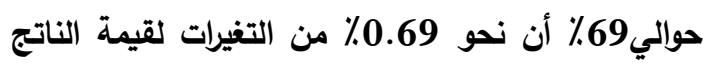
المحلي الزراعى تعزى إلى التغيرات للمستوي التكنولوجي.

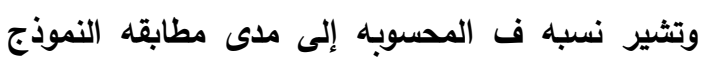
المستخدم إلى طبيعية البيانات موضع القياس.

رابعـاً: نتـائج تقدير النمـاذج القيـاســـيـة لأهم المتغيرات الاقتصــــاديـة المحدده لقيمـة

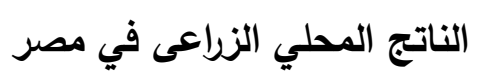

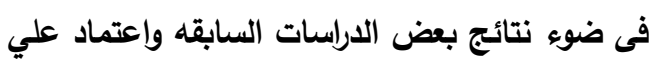
فروض النظرية الاقتصادية فقد تم حصر أهم المتغيرات الاقتصادية المحدده لقيمة الناتج المحلي الزراعى فى مصر النصر والموضحه بالجدول رقم (3) وهى: 1. قيمة الاستثمارات الزراعية بالمليار دولار 2. 1. 2. 3. 4. 5.

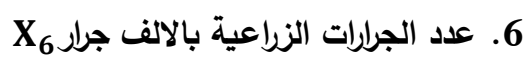
7. 8. قيمة الاستثمارات الزراعية فى العام السابق بالمليار دولار ر 
2- نتائج القياس الاحصائى للصوره النصف لوغاريتمية

تثير تقديرات المعادله رقم (28) بالجدول رقم (7) إلى نتائج القياس الاحصائى للعلاقه بين قيمة الناتج لباتج المحلي الزراعى وأهم العوامل المحدده له فى صورتها النصف لوغاريتمية خلال الفتره (2000-2018)، حيث الزئ يتبين أن أكثر العوامل تأثيرا علي قيمة الناتج المحلي

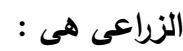

(1-2) قيمة القروض الزراعية أوضحت النتائج أن قيمة القروض الزراعية هى من النماعيه

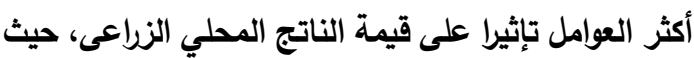
أشارت التقديرات إلى وجود علاقه طردية مؤكده احصائيا بين قيمة القروض الزراعية وقيمة الناتج المحلي الزراعى، حيث أنه بزياده قيمة القروض الزراعية بمقدار الوحده لزيه

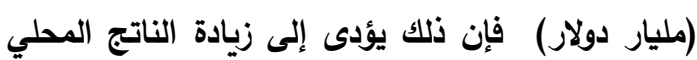

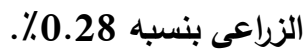

(2-2) المساحه المحصولية أثشارت النتائج أن المساحه المحصولية تحتل المرتبه المصوله المانه الثانية بين أهم العوامل المؤثره علي قيمة الناتج المحلي الزراعى، حيث أثشارت التقديرات إلى وجود علاقه طردية مؤكده احصائيا بين المساحه المحصولية وقيمة الناتج المحلي الزراعى، حيث أنه بزياده المساحه المحصولية

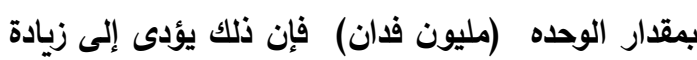
الناتج المحلي الزراعى بنسبه

$$
\text { (3-2) قيمة الصادرات الزراعية }
$$

أثشارت النتائج الموضحه بالمعادله رقم (28) بجدول رقم (7) إلى وجود علاقه طردية مؤكده احصائيا بين الناتج المحلى الزراعى كمتغير تابع وقيمة الصادرات الزراعية كمتغير مستقل، حيث أنه بزياده قيمة الصادرات الزراعية بمقدار الوحده (مليار دولار) فإن ذلك يؤدى إلى زيادة الناتج المحلي الزراعى بنسبه 0.09٪.
(1-1) قيمة الناتج المحلي الزراعى فى السنه (السابقه

أوضحت النتائج أن قيمة الناتج المحلي الزراعى فى المى المئه السنه السابقه (xi9) بالمليار دولار هى من أكثر العوامل

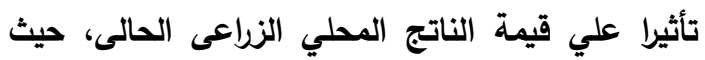
أثارت النتائج إلى وجود علاقه طردية مؤكده إحصائيا بين قيمة الناتج المحلي الزراعى فى السنه السابقه و قيمة

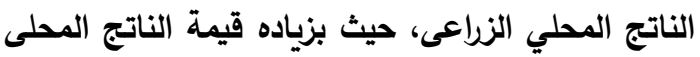
الزراعى فى السنه السابقه بمقدار مليون دولار فإن ذلك يؤدى إلى زيادة الناتج المحلي الزراعى بمقدار 710 دولار.

$$
\text { (2-1) حجم العماله الزراعية }
$$

أشارت النتائج أن حجم العماله الزراعية X

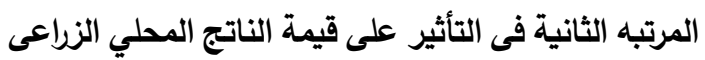
الحالى، كما تبين وجود علاقه طردية مؤكده إحصائيا بين هذا المتغير وقيمة الناتج المحلي الزراعى، وأنه بزياده حجم العماله الزراعية بحوالى مليون عامل فإن ذلك يؤدى النى إلى زيادة الناتج المحلي الزراعى بمقدار 3.69 مليار دولار.

$$
\text { (3-1) قيمة الاستثمارات الزراعية }
$$

أكلات النتائج إلى وجود علاقه طردية مؤكده احصائيا

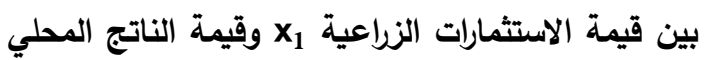
الزراعى وأشارت التقديرات المتحصل عليها أنه بزياده قيمة الاستثمارات الزراعية بحوالى مليار دولار فإن ذلك يؤدى إلى زيادة الناتج المحلي الزراعى بمقدار 4.24 مليار

وتثير التقدبرات المتحصل عليها أن معامل التحديد قد بلغ نحو0.90، الأمر الذى يشير إلى أن نحو 90٪ من

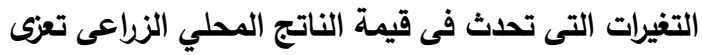
إلى التغير فى تلك العوامل المذكوره متجمعه.هذا وتثير فئه قيمة ف المحسوبه (70) إلى مدى مطابقه النموذج المستخدم لطبيعية موضع القياس. 
جدول رقم (7): نتائج القياس الاحصائي لأهم العوامل المؤثرة علي الناتج المحلي الزراعي المصري بالاسعار الحقيقية باستخدام الصور المختلفه لنماذج الانحدار المتعدد خلال الفتره 2000-2018

\begin{tabular}{|c|c|c|c|c|}
\hline F & $\mathbf{R}^{12}$ & النموذج القياسى & البيان & 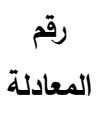 \\
\hline 70.0 & 0.90 & $\begin{aligned} y_{i}= & -15.34+0.71 x_{9}+3.69 x_{3}+4,24 x_{4} \\
(-2,31)^{*}(6,69) * * & (2,86)^{*}(2,35)^{* *}\end{aligned}$ & & 27 \\
\hline 173,7 & 0,97 & $\begin{aligned} \log y_{i} & =-0.33+0,09 x_{1}+0,28 x_{3}+0,12 x_{4} \\
(-0.61) & (2.61)^{*}(8,76) * *(8,23)^{* *}\end{aligned}$ & لوغاريتمى نصف & 28 \\
\hline 95.4 & 0.45 & $\begin{aligned} \log y_{i}= & -1.56+0,68 \log x_{9}+0,1.34 \log x_{3}+0,0.26 \log x_{1} \\
& (-3.69)^{* *}(8.44)^{* *}(4.67)^{* *}(2.67)^{*}\end{aligned}$ & لوغاريتمية & 29 \\
\hline \multicolumn{5}{|c|}{ 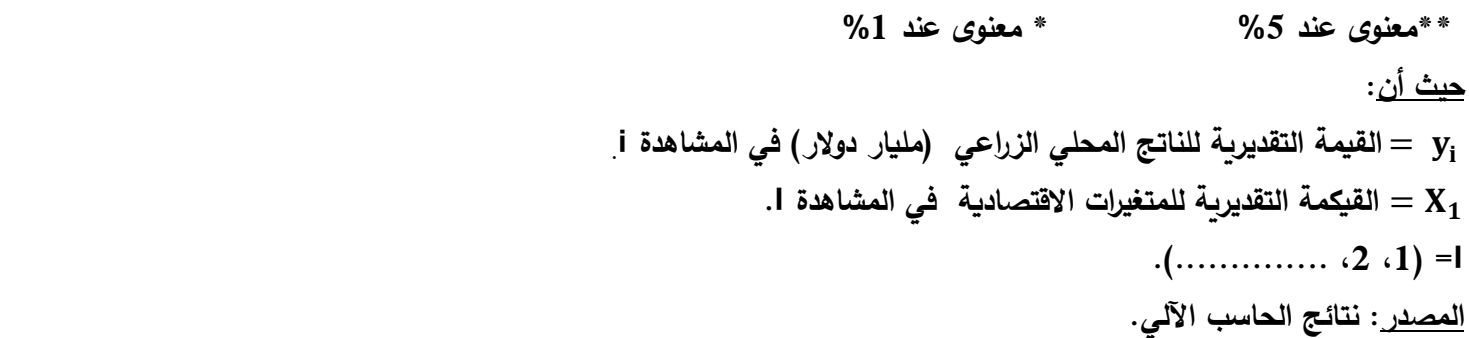 } \\
\hline
\end{tabular}

(1-3) له

أشارت النتائج أن قيمة الناتج المحلي الزراعى فى اله

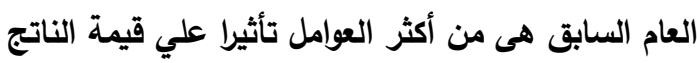

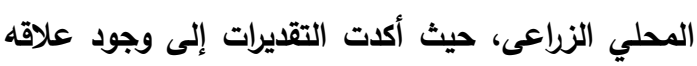

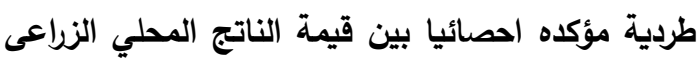

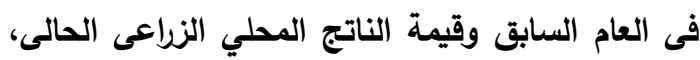

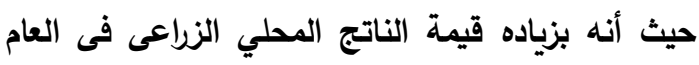

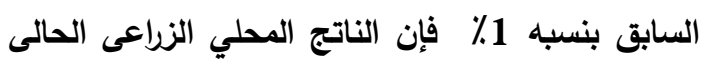

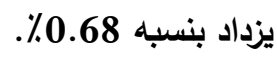

$$
\text { (2-3) حجم العماله الزراعية }
$$

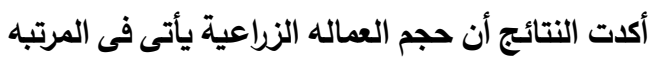

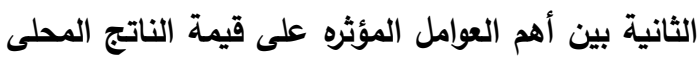
الزراعى. وقد أشارت النتائج إلى وجود علاقه طردية مؤكده

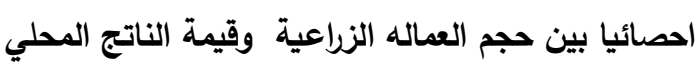

وتثير التقدبرات المتحصل عليها أن معامل التحديد

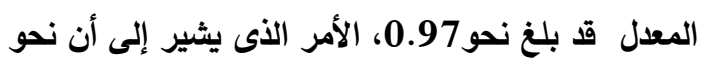
97 من التغيرات التى تحدث فى قيمة الناتج المحلي الزراعى تعزى إلى التغير فى تلك العوامل الثلاثه المذكوره. هذا وتثير قيمة ف المحسوبه (173.7) إلى مدى مطابقه النموذج المستخدم لطبيعية موضع القياس.

3- نتائج القياس الاحصائى للصوره الوغاريتمية المزدوجه

تثير تقديرات المعادله رقم (29) بالجدول رقم (7) إلى نتائج القياس الاحصائى للعلاقه بين قيمة الناتج

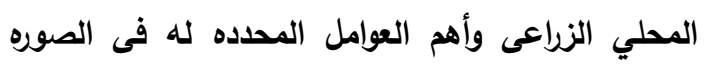

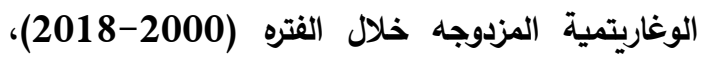
حيث يتبين أن أكثر العوامل تأثيرا علي قيمة الناتج المحلي الزراعى هى : التين ان 
الزراعى، وأنه بزياده حجم العماله الزراعية بنسبه 1\% المراجع:

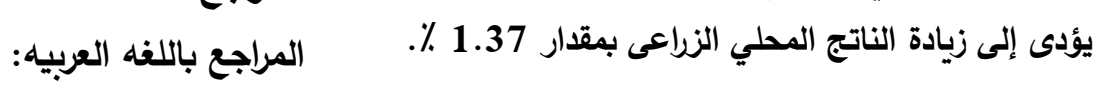
1. الجهاز المركزى للتعبئة العامه والاحصاء، الكتهاب: الكتاب الاحصائى السنوى، أعداد متفرقه.

(3-3) قيمة الاستثمارات الزراعية

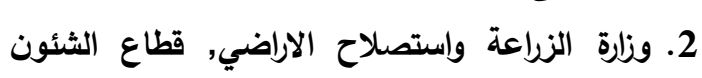
الاقتصادية, التجارة الخارجية, اعداد متفرقة 3.

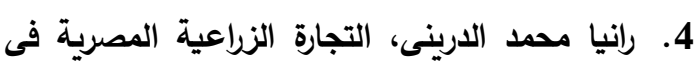

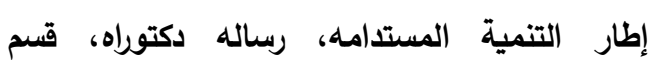

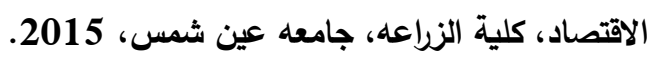

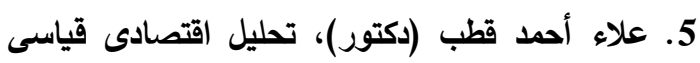

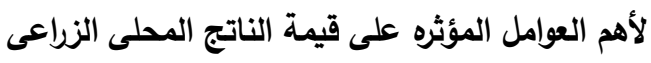
المصرى، مجله الأسكندرية للبحوث الزراعية، المجلد (18)، العدد (2)، 2016.

\section{المراجع باللغه الانجليزية:}

Boone. Jt. E.M., E.M. Boone and Cartin (1990S). Knowledge of Sustainable Agriculture Practices by Extension. Agents Virginia Journal of Extension, 2007.

أكلت نتائج المعادله رقم (29) فيمة الاستمارات المراعلية وجود علاقه طردية مؤكده احصائيا بين قيمة الناتج المحلي الزراعى كمتغير

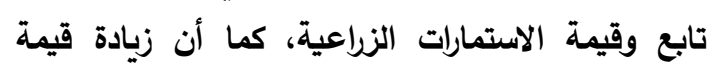
الاستثمارات الزراعية بنسبه 1\% يؤدى الإئى زيادة الناتج

$$
\text { المحلي الزراعى بمقدار } 0.26 \text { ٪. }
$$

وتثير التقديرات المتحصل عليها أن معامل التحديد

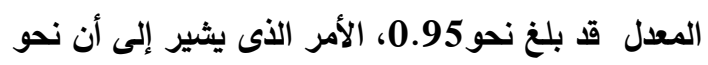

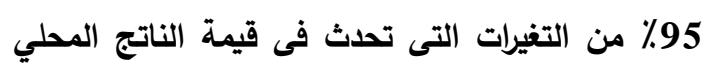
الزراعى تعزى إلى التغير فى تلك العوامل الثلاثه متجمعه. هذا وتثير قيمة ف المحسوبه إلى مدى مطابقه النموذج المستخدم لطبيعية موضع القياس. مما سبق تبين أن الصوره النصف لوغاريتمية هى

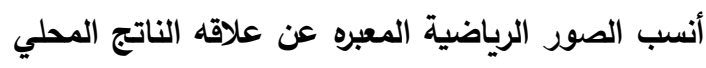

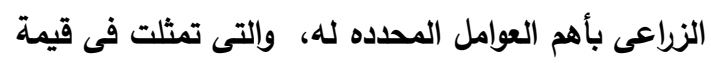
القروض الزراعية، المساحه المحصولية، وقيمة الصادرات الزراعية. 


\title{
ANALYTICAL ECONOMIC STUDY OF THE EGYPTIAN AGRICULTURAL GDP IN LIGHT OF LOCAL, REGIONAL AND INTERNATIONAL CHANGES
}

\author{
Shmoaa A. Mohammed \\ Department of Economic and Rural Development, Faculty of Environmental \\ Agricultural Sciences, Arish University
}

\begin{abstract}
The research problem is confined to the continuous decline of the contribution of agricultural GDP to the GDP, as this percentage decreased from about $15.5 \%$ in 2000 to about $11.2 \%$ in 2018.

The research aims, in general, to identify the performance of the Egyptian agricultural sector by studying the current status of agricultural GDP and determining the most important factors affecting it.

In achieving its objectives, the research relied on the method of descriptive and quantitative economic analysis, and also relied on the use of staged regression models to identify the most important factors affecting agricultural GDP, depending on the published secondary data issued by the Central Agency for Public Mobilization and Statistics, and the Central Bank of Egypt bulletins.

With regard to the determinants of agricultural GDP, the results indicated that the most important factors affecting the value of agricultural GDP according to the semi-logarithmic picture, which gave the best results were the value of agricultural loans, the crop area, the value of agricultural exports
\end{abstract}

Key words: GDP, Economical indicators, Economical Variables, Egyptian agricultural.

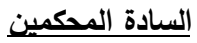

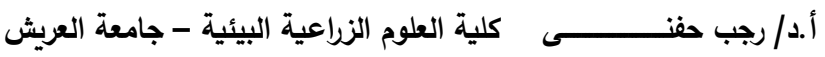

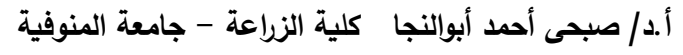

